Article

\title{
Migrants' Access to the Rental Housing Market in Germany: Housing Providers and Allocation Policies
}

\author{
Heike Hanhörster ${ }^{1}$ and Isabel Ramos Lobato ${ }^{2, *}$ \\ ${ }^{1}$ ILS-Research Institute for Regional and Urban Development, 44135 Dortmund, Germany; \\ E-Mail: heike.hanhoerster@ils-forschung.de \\ 2 Helsinki Institute for Urban and Regional Studies, Department of Geosciences and Geography, University of Helsinki, \\ 00014 Helsinki, Finland; E-Mail: isabel.ramoslobato@helsinki.fi \\ * Corresponding author
}

Submitted: 30 October 2020 | Accepted: 8 February 2021 | Published: 27 April 2021

\begin{abstract}
Housing markets play a decisive role in the spatial distribution of populations and the integration of immigrants. Looking specifically at Germany, shortages of low-rent housing in many cities are proving to be an open door for discrimination. This article looks at the influence institutional housing providers have on migrants' access to housing. Based on 76 qualitative interviews with housing experts, politicians, local government officials, civil society and academics, the internal routines of housing companies are examined for the first time in a German context, looking at what effect they have on producing socio-spatial inequality. Using Lipsky's (1980) 'street-level bureaucracy' as our conceptual framework, we argue that the barriers denying migrants access to the rental housing market are attributable to two factors: the organisational culture, whether in the form of official guidelines ('policy as written') or of day-to-day activities in the front-line context ('policy as performed'), and the huge gap between the two. Corporate policies, the resultant allocation policies, staff training and housing company involvement in local governance structures play a decisive role in determining migrants' access to housing. The goal of achieving the right social mix and the lack of guidelines for housing company staff in deciding who gets an apartment-turning their discretionary power into a certain kind of 'forced discretion' -in many cases arbitrarily restrict access to housing in Germany. Theoretically embedding these findings in organisational sociology, the article adds to urban geographical and sociological research into the drivers and backgrounds of residential segregation.
\end{abstract}

\section{Keywords}

allocation policies; discrimination; diversity policies; housing market; institutional housing providers; migration-led institutional change; social mix; street-level bureaucracy

\section{Issue}

This article is part of the issue "Migration-Led Institutional Change in Urban Development and Planning" edited by Robert Barbarino (TU Dortmund University, Germany), Charlotte Räuchle (Free University Berlin, Germany) and Wolfgang Scholz (TU Dortmund University, Germany).

(C) 2021 by the authors; licensee Cogitatio (Lisbon, Portugal). This article is licensed under a Creative Commons Attribution 4.0 International License (CC BY).

\section{Introduction}

"Our intention was just to protect you from being rejected and discriminated by the other residents in the block and the surrounding neighbourhood."

This was what a housing company cited as the reason for rejecting a Turk applying for a flat in a predomi- nantly native German neighbourhood. As in many other countries in Europe, there has been a decades-long political and academic discourse in Germany on the effects of social and sometimes explicit ethnic segregation and on ways of combating it. Much research highlights the benefits of living (at least temporarily) in migrant neighbourhoods ('urban enclave'; Zhou, 2009), pointing to forms of voluntary (ethnic) segregation 
based on migrants' housing preferences, e.g., regarding local networks or migrant infrastructures (Hanhörster \& Wessendorf, 2020). However, a critical view of ethnic segregation remains dominant in local housing policy. Though official quotas and maximum migrant ratios in German social housing belong to the past, many housing companies continue to steer housing allocation towards a 'healthy' mix. While some discourses explicitly highlight the need to avoid 'ghettos' or 'parallel societies,' they are more often disguised under the cloak of avoiding pockets of impoverishment. How housing companies go about selecting their tenants is embedded in organisational structures and day-to-day routines. These and their influence on migrants' access to the housing market have as yet hardly been researched.

Testing studies reveal the discrimination of migrants on the German housing market (Auspurg, Hinz, \& Schmid, 2017; Horr, Hunkler, \& Kroneberg, 2018). Indeed, a representative survey in Germany has revealed that the selection of tenants is not based solely on objective urgency, but also on such subjective factors as (perceived) origin, difference and suitability (Antidiskriminierungsstelle des Bundes [ADS], 2020). This can have dramatic consequences, as housing plays a key role in integration (Ager \& Strang, 2008).

The social mix principle is gaining in relevance in Germany due to the increasing polarisation of society (Helbig \& Jähnen, 2018) and the recent influx of refugees. What remains unclear however is what is understood by the 'right' mix, especially in the face of high immigration rates and superdiversity (Vertovec, 2007). Further questions ask which organisational routines steer tenant selection and whether or rather how increased diversity is leading to organisational change or persistence of inner routines in housing companies. The question also arises as to whether the goal of achieving a mix is compatible with the objective of non-discriminatory letting enshrined in the German General Equal Treatment Act (Allgemeines Gleichbehandlungsgesetz; Federal Anti-Discrimination Agency, 2006) which entered into force in 2006. It is therefore important to better understand the role of housing companies in the production of inequality and to scrutinise how local organisations like housing companies are reacting to increasing levels of diversity.

Spotlighting Germany, the article looks at the internal routines of housing companies for the first time, assessing how they influence migrants' access to housing, and, subsequently, the production of socio-spatial inequality-a topic in need of a lot more discussion and further investigation. We thereby include the perspective of organisational sociology in the urban geographical and sociological research on drivers of segregation. The concrete research questions are as follows: a) Which internal and external factors influence or hinder migration-led organisational change and/or the persistence of company routines governing the access to housing for migrant households? And b) What influence do institutional housing providers consequently have on (re-)producing socio-spatial inequality?

\section{Setting the Context: The Social Mix Principle and Migrants' Access to the German Housing Market}

With a view to combating continuing segregation, the planning policy principle of achieving the right social mix has gained prominence in various (European) countries (Münch, 2009). The main aim here is to create and maintain socially stable occupancy structures-a great challenge for the many countries hosting increasing numbers of refugees since 2015 (Darling, 2016). Germany is no exception in this respect, with the principle of a 'healthy' residential mix enshrined in various federal laws and strategic plans (Die Bundesregierung, 2007) and guiding the activities of many different players. Indeed, in many ways it is seen as common sense to give local players sufficient room for manoeuvre. This principle is currently being questioned especially in academic circles, as is the strong focus on socially deprived neighbourhoods. Dependent on low-price housing, new immigrants with few resources are being hit particularly by selection strategies.

The German housing market, especially in large cities, is characterised by a comparatively high share of rental apartments (58\% of the total housing stock; Statista Research Department, 2020) in the hands of institutional housing providers and private owners. The term 'institutional housing providers' covers three institutional forms: municipal housing 'companies,' private housing companies and cooperatives. Overall, institutional housing providers (vs. individual owners) represent $42 \%$ of the rental and $22 \%$ of the total housing stock nationwide (Statistische Ämter des Bundes und der Länder, 2019).

In total, there is a shortage of 1,9 million flats in Germany's 77 major cities (with more than 100,000 inhabitants). Consequently, more than a quarter of all households in these cities are undersupplied (Holm \& Junker, 2019, p. 2). This situation predominantly affects low-income households, as construction of social housing, long the key to housing for low-income households, has experienced a sharp decline in Germany in recent years, dropping from 2,09 to 1,14 million apartments between 2006 and 2019 (Statista Research Department, 2021) and thus no longer able to meet demand. Waiting times of several years are consequently the rule, especially for larger families (many of which are migrant families). They also limit housing seekers' options spatially, as social housing is often concentrated in disadvantaged neighbourhoods, in contrast to affluent residential areas where fluctuation rates (and thus opportunities to move in) are particularly low. Due to these enormous bottlenecks, many households qualifying for social housing are forced to look for housing on the private market where insufficiently restrictive regulation has led to exploding rents, especially in many inner-city neighbourhoods. In a 
few cities, attempts are being made to curb drastically rising prices through rent ceilings (e.g., Berlin).

The influx of refugees in recent years has exacerbated housing bottlenecks, with many refugees forced to stay in temporary accommodation in several German cities. A recent study of the socio-spatial distribution of migrants between 2014 and 2017 (Helbig \& Jähnen, 2019) revealed that in all the 86 cities studied, the proportion of migrants increased most in the socioeconomically most disadvantaged neighbourhoods. Although we obviously cannot establish any direct causal relationship between these findings and housing companies' allocation practices, what we can say is that supply bottlenecks can create an environment fuelling discrimination: As almost every second household is entitled to social housing in large agglomerations, allocation procedures based on urgency are often prone to discrimination in the face of marginal fluctuation and vacancy rates (Hanhörster, Droste, Ramos Lobato, Diesenreiter, \& Liebig, 2020). Cole and Furbey (1994, as cited in Tomlins, 1997, p. 181) even go as far as to argue that "allocation in a context of scarcity requires discrimination." Measured by requests for counselling, ethnic discrimination is the commonest form of discrimination in Germany (ADS, 2020, p. 5). Some 35\% of migrant interviewees spoke of having experienced discrimination on racist grounds or because of their ethnicity in the past 10 years when searching for housing. Many cases involved multiple discrimination due to their low household incomes. In other European countries as well, a (perceived) migration background is acknowledged as a hindrance when looking for housing (Dill \& Jirjahn, 2014; Sala Pala, 2013). This often affects even high-skilled middle-class migrants (Hanhörster, 2015).

In contrast to other European countries, in Germany there is little focus on structural discrimination in the allocation of housing to migrants (Münch, 2009). Although the General Equal Treatment Act provides the legal footing for equitable access to the housing market, it contains several loopholes allowing the discriminatory allocation of housing, for example the clause that protection against discrimination needs not be respected when a landlord is intent on creating and maintaining "stable social structures" (Federal Anti-Discrimination Agency, 2006). There are also different forms of discrimination. Whereas direct discrimination covers practices directly related to such personal characteristics as gender or religion, indirect discrimination is based on apparently neutral criteria which nevertheless cause the discrimination of certain social groups (ADS, 2019, pp. 22-23). Allocation in the sense of a 'good mix' may be understood as a form of indirect discrimination when it is based on stereotypes of certain groups or prejudices against them. Here again, there is a clear lack of studies of the German context with a spotlight on the discriminatory effects of company policies and selection strategies.

\section{Housing Companies as Producers of Socio-Spatial Inequality}

Access to functional resources (e.g., jobs or housing) is influenced not just at a macro level through societal framework conditions or political principles, but also at a meso, i.e., an organisational level, as represented by schools or housing companies. In doing so, organisations not only reflect societal structures, but also generate the structures, institutional systems and hierarchies found in cities. A wide range of definitions are used in reference to the terms 'institution' and 'organisation.' We use the definition provided by Allard and Small (2013, p. 9), whereby 'organisations' are "formally recognized sets of people and practices whose activities are oriented toward an overarching purpose." By contrast, 'institutions" are umbrella systems, as "sets of individuals, organizations, and networks of relations that structure major aspects of urban life." In this article, we understand housing companies as organisations and as components of the institutional housing system, i.e., as "players of the game, and as they pursue their objectives, they act as agents of institutional change" (North, 1990, as cited in Kingston \& Caballero, 2009, p. 154).

Few studies have been conducted in urban sociology or geography on the power of organisations to (re-)produce or counter inequality: The "theoretical implications of the social productivity of organizations are mostly undeveloped despite the growing interest in confronting this issue head on" (in criticism thereof, cf. Allard \& Small, 2013; McQuarrie \& Marwell, 2009, p. 262). In his concept of 'street-level bureaucracy,' the political scientist Michael Lipsky (1980) highlights this structuring power of organisations, also reflected in the amount of discretion available to front-line staff. He refers to the gap between an organisation's official guidelines ('policy as written') and how these are interpreted by front-line staff in their day-to-day work ('policy as performed'):

In the context of organisational change, these two levels are described as the formal and the informal levels: The term 'formal' is often taken to mean that the rules are made explicit or written down, particularly if they are enforced by the state, whereas informal rules are implicit. (Kingston \& Caballero, 2009, p. 154)

Lipsky's concept can be used in reference to migrationled change on the housing market, illustrating the reciprocal effects of but also the contradictions in dealing with growing diversity between the formal objectives and the day-to-day work of front-line staff.

Building on Lipsky's (1980) 'street-level bureaucrats' concept, we now look at the role of housing companies and the discretion available to them in dealing with diversity. 


\subsection{Organisational Culture: 'Policy as Written'}

Organisations such as institutional housing providers differ not only in their formal structures (e.g., in the purpose enshrined in their articles of association), but also in their informal, normative, and cultural properties. Guiding corporate operations, these two different (more or less visible) dimensions of organisational culture are described by McQuarrie and Marwell (2009, p. 258) as the "dual nature of organisations." Similarly, Lipsky argues that it is not a company's formal organisational structure, which influences how customers are handled, but its day-to-day routines, attitudes, and values, which are not necessarily reflected in written documents. Looking at the dynamics of corporate policies, HR policies or codes of ethics, we are also seeing a change. Organisational change in reaction to rising immigration and diversity is in some cases enshrined in diversity management policies. It could even be the result of a combination of factors: Organisations are shaped in their structure and their change by "organisational actors," i.e., those who, through their values and attitudes, have a decisive influence on the functioning of organisations and are able to change them "from within" (Pahl, 1975, p. 265). A further factor could be a corporate target to counter discriminatory behaviour towards specific groups (Dobusch, 2017, p. 1645).

Yet organisations do not represent a homogeneous system but are instead the products of the social categories and norms determining their systemic and institutional embedding. Looking specifically at discrimination in people's access to resources, it is of decisive importance to look exactly at how organisations operate: "The fewer the resources to which people have access, the more their circumstances will depend on the organizations in which they participate" (Allard \& Small, 2013, p. 6).

\subsection{Day-to-Day Practices: 'Policy as Performed'}

With his term 'street-level bureaucracy,' Lipsky refers to the day-to-day practices of company staff, while his term 'policy as performed' refers to staff's discretion in applying rules and procedures. Similarly, he used the term 'street-level bureaucrats' in reference to "public service workers who interact directly with citizens in the course of their jobs, and who have substantial discretion in the execution of their work" (Lipsky, 1980, p. 3). According to Lipsky, corporate policies are never executed homogeneously in the field. Instead, execution takes place in a context of 'bounded rationality,' where staff weigh up the interests of company management and those of their customers (Kingston \& Caballero, 2009). Against a backdrop of limited resources, front-line company officers do their best to adapt their daily workload to their available resources. Categorising customers and prioritising their needs in a discretionary way are two ways of doing so. Differentiating between the 'deserving' and the 'unde- serving' (Katz, 1990) is shaped by their experiences and their respective (subjective) values/prejudices and solutions available.

Yet only few empirical studies have looked at the internal routines of housing companies (Rosen, 2014; Sala Pala, 2013; Tomlins, 1997). These tend to view housing company staff as 'gatekeepers' to the housing market, wielding discretionary power over the allocation of housing to migrants. Especially when affordable housing is in short supply, the prioritisation of candidates and thus the decision-making discretion of housing company staff assume a key role.

\section{Methodology}

This contribution is based on the findings of a research project (concluded in 2019) analysing the practices of institutional housing suppliers regarding allocating housing to migrant households in Germany. Despite increasing pressure on the rental housing market through the recent influx of refugees in Germany (particularly in the low-price segments), the project's focus was not explicitly on refugees.

In a first project phase, 29 interviews with 38 housing market experts were conducted. Focused on large cities (with more than 100,000 inhabitants), the interviews covered experts throughout Germany, for example those working in umbrella organisations, as well as interviews with politicians, local government officials, academics, and civil society representatives (antidiscrimination agencies, tenant associations, migrant organisations, etc.). As there are as yet only few housing guidelines on diversity in Germany, housing companies with a certain amount of expertise in this field were particularly called on to contribute to the analysis.

In a second project phase, 47 further interviews were conducted in three case study cities with experts from the previously mentioned groups. The selected citiesBerlin, Dusseldorf, and Hamburg-are state capitals and greatly influenced by migration, as reflected by their high proportions of migrants (Berlin: 34\%; Dusseldorf: 35\%, Hamburg: 41\%; national average: 26\%; Hanhörster et al., 2020, p. 12), whereby people of Turkish origin constitute the largest group. The pressure on their housing markets is reflected in the high rate of households having to spend at least $40 \%$ of their net income on rent (excluding utilities and heating). Moreover, they all have a high rate of housing undersupply, especially for low-income households (Holm \& Junker, 2019). To counter the pressure on the rental market, rent control instruments are used in all three cities.

Lasting 1-1.5 hours, the semi-structured interviews followed a guideline with six core questions and a series of in-depth questions allowing for modifications according to the interviewees' different work contexts. Alongside those on corporate policy towards diversity, questions focused on policy execution, for example in the form of allocation strategies and the prioritisation of 
certain groups, and on socio-spatial cooperation projects. Within the housing companies in these three cases studies, staff from different hierarchy levels (corporate management, middle management, front-line staff) were interviewed. Because of the sensitive study topic and difficulties in gaining access to housing companies, we were unfortunately unable to observe the day-to-day work of front-line staff. In consultation with our interview partners, all results were anonymised.

All interviews were fully transcribed and then both deductively and inductively encoded. We are aware of the danger of conflating self-reports with behaviour assuming a consistency between people's attitudes and their actions (Jerolmack \& Khan, 2014). What people say is often only a poor predictor of what they do. Therefore, we deliberately contrasted the housing company interviews with those conducted with other expert groups. Moreover, we used further methods to review and reflect upon the interview findings, including an analysis of housing company websites and documents on corporate policies, allocation strategies, etc. This was rounded off by a focus group discussion involving various stakeholder groups in all three case studies and a joint closing event.

\section{Migrants' Access to Housing Markets: Organisational Guidelines and Their Execution in Practice}

In line with the discussion above on Lipsky's 'street-level bureaucracy,' we argue that the institutional barriers for migrants on the German rental housing market belong to two areas: the organisational culture and the official diversity policies of housing companies ('policy as written') and day-to-day front-line practice ('policy as per- formed'). With reference to the latter, we make a distinction between three different dimensions based on our interview findings: staff policy and customer relations management, allocation management and the embeddedness of housing companies in cooperation and governance structures (see Figure 1). Building on this distinction, we will now look at the interaction between these two areas, discussing which factors promote or hinder organisational change in housing providers in the sense of providing migrant households with better access to housing or the persistence of inner routines.

\subsection{Organisational Culture and Diversity Policies: 'Policy as Written'}

Diversity management started moving up corporate agendas in the 1990s. Yet with no set definition of the concept, there is a lot of critical discussion on the extent to which it actually contributes to a questioning of existing power structures (Ahmed, 2007; Janssens \& Zanoni, 2005): “The term 'diversity' is appealing as it does not necessarily challenge organizational culture, even if it allows a change in appearance" (Ahmed, 2007 , p. 606). Over the past few years, several larger housing companies have introduced diversity management policies (Bundesverband deutscher Wohnungsund Immobilienunternehmen e. V [GdW], 2015) focused on HR management, better migrant access to housing and the promotion of intercultural neighbourhoods. This is witnessed by such wordings as "corporate culture alignment with diverse cultures," or "staff training in intercultural competences" (GdW, 2015). Thus, the question arises whether these guidelines upheld by the GdW as the sector's umbrella organisation are actually leading

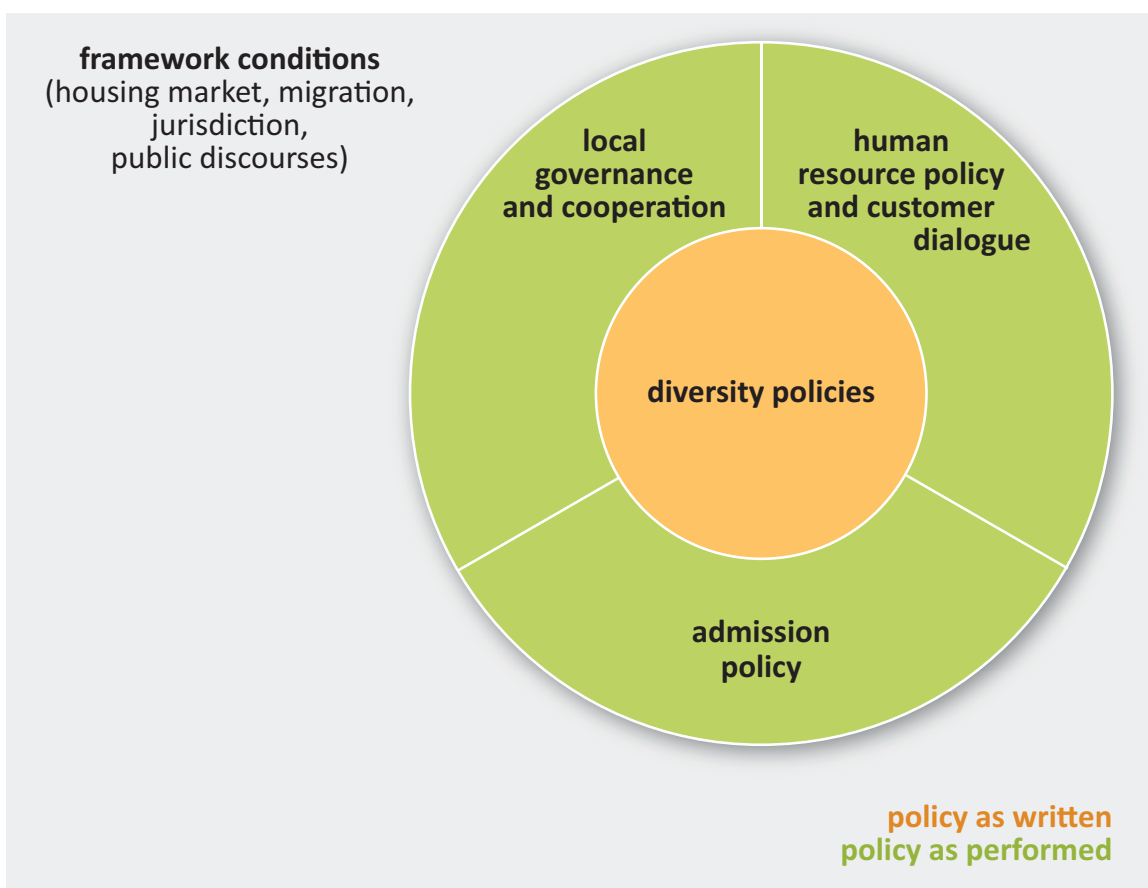

Figure 1. 'Policy as written' and 'policy as performed' in the field of housing. 
to changed attitudes in dealing with diversity and to structural changes in corporate practices.

Our interviews revealed that very little is currently being done to actively promote diversity in the German housing sector. Drilling deeper, we found that not one of the companies upheld by experts as best practice examples had any concrete guidelines on how to handle diversity. While in some cases equal treatment topics are at least indirectly communicated to staff-for example with the staff photos of several companies showing people of different colours-ethnic diversity was not explicitly stated as a corporate objective by any of the top executives interviewed. With just a few exceptions, all corporate hierarchy levels are staffed solely by native Germans. At the same time, the availability of in-house intercultural training to promote equal opportunities was frequently cited as a way of increasing staff awareness to the subject.

In addition, diversity policies are supposed to address the transparency of criteria in allocating housing. This is a key issue, as-in the words of one civil society interviewee-the tight housing market "makes it very, very easy [for housing companies] to reject candidates on totally obscure grounds when they want to do so." As our interviews revealed, there is very little awareness of any discriminatory structures on the housing market. The presence of organisational barriers is denied by housing providers and in many cases the issue is taboo. Direct forms of discrimination are passed off as a 'one-off phenomenon,' while indirect discriminatory structures, e.g., a rejection due to a candidate's lack of German language skills, are not even seen as such.

The lack of awareness for discriminatory structures on the housing market makes it difficult to initiate any constructive and meaningful discussion on access barriers. As a result, little if any use is made of discretionary leeway (e.g., the development of guidelines for the whole sector). This applies especially to allocation practices, which continue to be oriented towards achieving the 'right' social mix. Targeted allocation management is seen as the basis for successful letting and effective operations, as it is considered the best way to minimise conflicts, keep fluctuation (and the resultant knock-on costs) at a tolerable rate and to cut the need for socio-spatial measures. Behind the stated goal of maintaining or creating 'stable and healthy neighbourhoods,' we thus generally found the microeconomic goal of efficient letting. For example, one executive stressed that his company attached:

Great value to maintaining a balance in the neighbourhoods. What is the point of letting everyone move in... with the result that at the end of the day the social mix goes down the drain. Then I've quickly got a real problem on my hands.

It was also interesting to note that, despite their key importance, none of the companies had any clear idea what exactly was meant by the 'right' social mix. As only few of the housing companies studied had clear allocation criteria (apart from urgent cases, e.g., where tenants were faced with the imminent loss of their flat), tenant selection was ultimately left in the hands of front-line staff: "We don't have any corporate policy for allocating housing....It's up to team leaders to come up with the right allocation strategies and the right target groups, all in an attempt to achieve the right balance in every neighbourhood." As this statement showed, executives often deliberately refuse to set up any concrete guidelines but rather expect front-line staff to both know and follow an unwritten code (similar to explanations on 'informal rules' by Kingston's \& Caballero, 2009). Thus, the scope of discretion usually enabling frontline staff to deviate (slightly) from a written policy (Lipsky, 1980) turns into a form of 'forced discretion' masking the lack of guidelines. It was quite clear that any changes of internal routines or policies were dictated by corporate management, with the latter thus having a decisive influence on the corporate philosophy and on how open the company was to new groups. One executive for example had this to say: "If I thought it would be best for us to batten down hatches, we'd have no problem doing so." It should be remembered here that the HR structure of corporate management has a great influence on corporate policy: "We here have something very special, something you won't usually find in the housing sector [executives with a migration background]. It's also something we try to achieve in our teams."

The attitudes of corporate management have not only a decisive impact on internal processes and structures, but also on their cooperation with external partners. The growing tightness of housing markets and the major influx of refugees in 2015/2016 have led to new strategic alliances in the housing sector. Many executives told us that they were being increasingly involved in city and neighbourhood committees dealing with social issues. This development also encompasses the heightened involvement of civil society players, often taking the form of formal cooperation agreements.

We now move on to discuss whether the organisational change emerging in some companies regarding an increasingly diversity-oriented corporate philosophy is just lip service or is actually triggering a long-term change in internal company structures and practices.

\subsection{Organisational Practices: 'Policy as Performed'}

\subsubsection{HR Policy and Customer Relations}

Systematic diversity management is reflected in diversityoriented staff training and communications with customers. The following quote from a housing company executive makes it clear what lasting difference a diverse management team can have on a company's corporate communications culture: "That's something we try to achieve in our teams. Given the constellation here, 
I don't think that one could openly speak of any [prejudice against people with a migration background] in our house." This statement applied to both corporate management and staff. Even if staff with a migration background do not per se have intercultural skills and are, like all other staff, very likely to use categorisations to make their work easier (Jeffers \& Hoggett, 1995), a more diverse staff structure would seem to promote reflective attitudes and greater openness in internal communications, while at the same time countering the perception of migrants as 'bad' tenants. Nevertheless, few housing companies specifically hire employees with a migration background to take account of the growing diversity of their customers and thereby to position themselves as service-oriented companies (Meziani-Remichi \& Maussen, 2017).

Alongside the hiring of staff, awareness-raising measures among existing staff play a decisive role in driving any organisational change towards taking greater account of diversity. However, while diversity training is available to staff in some companies, little seems to have actually taken place in the field of raising awareness among existing staff and training them. A further interesting point is that the wish to further develop intercultural skills does not always seem to come from corporate management, but often from front-line staff, in many cases reflecting uncertainty with how to deal with specific groups. However, these needs do not always lead to action by corporate management.

Customer relations are a further touchstone of a company's diversity management. Despite the new intercultural openness proclaimed by them, the housing companies studied continue to uphold equal treatment (but not equal opportunities) when advertising vacancies, while at the same time presenting them on the usual platforms almost solely in German. Easy-to-read information in different languages, whether in the form of flyers, face-to-face counselling, hotlines, etc., is often also lacking. Even if some committed companies work with interpreters and multilingual info material, these measures were only strictly pursued in very few cases and only introduced on efficiency grounds (in particular when language difficulties resulted in knock-on costs for the company). Yet despite all these measures, poor knowledge of the German language remains a key handicap on the German housing market-even among large institutional housing providers, as the following quote from a frontline worker illustrates:

When people contact us via e-mail, you easily recognise...by their style of writing...that they speak and write German badly....So it [the application] moves automatically to the back of the queue and you first have a look at those able to write an understandable sentence.

For recently arrived refugees in precarious socioeconomic circumstances, this leads to a particularly vul- nerable situation. Generally speaking, it was clear that the much-proclaimed corporate image of a nondiscriminatory housing company had in most companies not led to any systematic organisational change. Any diversity-oriented commitment usually took the form of 'flagship projects': good for polishing a company's image, but of little actual use in the field.

\subsubsection{Housing Allocation}

Targeted allocation management by front-line staff is seen by the housing sector as a key factor in successful letting. Alongside objective criteria, such as a candidate's creditworthiness, subjective criteria are also used by staff to decide who gets an apartment. The 'healthy' social mix policy defines the framework for such allocations, without however defining any specific criteria. Our interviewees took a formal stance, defining social criteria in the sense of achieving the right mix of income groups. But there were also explicit references to ethnic categories and-at least in the discussions with us-the companies' clear concern to prevent "ghettoization." For example, potential conflicts between different nationalities or ethnic groups and their low mutual "compatibility" were often cited as grounds for specific allocations or rejections:

We do try to make sure that certain ethnic groups do not live together in the same block of flats. In my view, things never work out that well between North Africans and Russians. It's no secret that you've got to keep an eye on such aspects.

The phrase ("in my view") illustrates the importance of front-line staff individually classifying candidates, just as the appeal to use common sense (implicit in the phrase "it's no secret that") is synonymous with legitimisation (Dobusch, 2017).

Although rejections are now generally worded to conform with the General Equal Treatment Act, our interviews revealed a universal misinterpretation of the clause that exceptionally allows unequal treatment when letting housing. The goal of this derogation is to allow the use of positive measures (e.g., quotas) to offset discrimination on the German housing market, especially for people with a migration background. However, many of the housing companies interviewed saw this derogation as legitimisation for specifically rejecting candidates with a migration background. The fact that the goal of achieving the right social mix ultimately led to migrant households not being selected was either ignored by the companies interviewed or at least not addressed.

Nearly all allocation decisions are taken at team leader level or below. Front-line staff are guided by a candidate household's assumed 'suitability,' i.e., whether a household is seen to fit in with the composition of residents in a block of flats or housing estate. On account of competition between various 'vulnerable' groups on 
the housing market, front-line staff are forced to weigh up whether a candidate belongs to a 'deserving' or to an 'undeserving' group (Katz, 1990). The 'suitability' decision is discretionary, with front-line staff deemedaccording to the interviewed executives-to have sufficient knowledge of local conditions and the housing on offer: "The final decision is based on the gut feeling of the customer centre manager." "Gut feeling," "sufficient knowledge," and "experience" are thus seen to be the key factors for targeted allocations (GdW, 2015). On account of their discretionary power, front-line staff play a key role in the allocation process, becoming gatekeepers to housing. The discrepancy described by Lipsky (1980) between formal instructions ('policy as written') and their day-to-day execution ('policy as performed') has thus less to do with the discretion accorded to frontline staff and more to do with the lack of written instructions, forcing staff to step in and take decisions based on their own criteria. Front-line staff's discretionary power thus becomes a form of 'forced discretion.' Clear criteria can be assumed to facilitate allocation and to 'relieve' front-line staff from having to use this 'forced discretionary power,' as illustrated by the following quote from an employee working for the only company interviewed with a clear set of criteria:

The good thing for me is that I can be fair because, if I just followed my nose, it would be easy for me in some situations but difficult in others. Thus, I would just not give an apartment to people with whom I am not on the same wavelength....And like this [with the set of allocation criteria implemented by the company] I have a tool that enables me to say that I treat everyone equally.

Nevertheless, the term 'forced discretion' should not disguise the fact that both executives and front-line staff see personal assessments and experience as indispensable for targeted allocations. The fact that the criteria established by front-line staff are obviously based on subjective factors is thus not seen as any great problem, as revealed by the following quote from an executive: "Staff...are obviously guided by their own, personal taste. If I have the feeling that the candidate sitting opposite me fits in better because he will not cause me any trouble, then obviously I'll plump for him." Many front-line staff try hard to create micro-neighbourhoods with little potential for conflicts and consequently with the expectation of low fluctuation: "Each new rental contract...can land in a court or cause a complaint, meaning more work for us. We are all by nature lazy. If I select the wrong candidate, I'll end up with more stress."

Consequently, the interpretation of what constitutes a 'healthy mix' is also dependent on the neighbourhood in question. The quote at the beginning of this article illustrates that allocation practices make it difficult for migrants to gain access to housing in areas with a dominant middle-class and native German composition.
Allocation decisions not only make it more difficult for certain groups to gain access to specific housing, but also reduce transparency for candidates:

I can't just say: "I don't want you." I have to think up an excuse why I wasn't able to select that personI mustn't discriminate. As front-line staff, we need a good dose of sensitivity and skill. Things like: How can I speak with someone? How much plain speaking can he take? How can I put that another way?

This quote highlights the desire of staff (despite a certain lack of decision-making transparency) to justify their decisions. As argued by Kozica, Kaiser, and Friesl (2014, p. 18): "Actors orient their behavior in accordance with the potential requirement to justify it." Discrimination on the housing market is thus not necessarily an expression of racist attitudes. In many cases, it just reflects a desire to make things easier for staff: "the social actors do not need to be racist to discriminate" (Sala Pala, 2013, p. 180). This makes it all the more difficult to uncover forms of discrimination in allocating housing. However, there is little readiness on the part of the housing companies to make allocation processes more transparent, despite formally upholding diversity in their corporate policies. Interestingly, this also applies to municipal housing associations, whose commitment to provide social housing is, as already discussed, much stronger than that of private or cooperative housing providers. Systemic changes to corporate structures are thus inconsistent and seemingly unwanted. Moreover, no audits had yet been conducted in any of the companies studied to check whether their allocation practices were in line with their increasingly diversity-oriented policies.

\subsubsection{Local Governance Structures and Cooperation}

Alongside federal legislation and guidelines, organisational change in housing companies is being driven by the political climate and the involvement of these companies in local governance structures. Both interviews and focus group discussions revealed that the influx of refugees in the past few years has increased awareness towards housing companies' allocation practices in the context of housing and integration policies. Pressure to legitimise their allocation strategies and practices has grown, especially in municipalities with strong antidiscrimination policies, migrant self-help organisations and tenant initiatives. In this respect, the provision of housing for refugees has acted as a catalyst for organisational change in housing companies.

But even if these cooperation projects point to clear organisational change on the part of housing companies, our interviews revealed a more ambivalent picture. Migrant organisations and NGOs are often portrayed in the glossy brochures published by the housing companies as key neighbourhood development partners with whom strategies are jointly developed to address 
diversity. Our study revealed however that, while civil society representatives are in some cases involved, they do not do so on an equal footing, as for example the following statement made by a housing company executive illustrates: "[We don't want] welfare associations influencing our core business. As long as both sides accept this, everything is ok." In many cities, cooperation projects with local authorities were little more than expressions of interest, with no binding strategies or targets being set to improve migrants' access to housing and no discussions being held over the effects of social mix strategies. Allocation management thus remains solely in the hands of the housing companies. Consequently, we were unable to note any change in company practices aimed at making housing allocation more transparent and thereby less discriminatory, such as the conduction of regular quality audits or joining of forces, e.g., on regional platforms.

At the same time, however, any cooperation between the housing sector and politics/local government seems to be also dependent on a municipality's interest in doing so or on its problem awareness, as shown by the following quote of a company executive:

As regards such activities here in Dusseldorf, we are not doing as much as in other municipalities, inter alia... because the authorities here are not that active in the field of neighbourhood development or integration. The willingness to work together, to network, to develop neighbourhoods is much higher in municipalities subject to structural change....Dusseldorf is booming. Why change things?

Our interviewee attributed Dusseldorf's apparent lack of interest in neighbourhood development to the city's comparatively privileged socioeconomic situation. Interestingly, in this case any willingness to cooperate and show more socio-spatial commitment would seem to be hindered by a lack of interest on the part of external cooperation partners; here, the municipality itself. By contrast, key changes, e.g., the social realignment of municipal housing associations, are taking place in Berlin, driven by strategic political alliances and state legislation. An important role has been played here by local stakeholders such as Berlin's anti-discrimination agency which managed to involve the housing sector in discussions with other stakeholders and supported housing companies in developing strategies to deal with diversity. This organisational change is being driven not only by cooperation projects with civil society, but also by the operations of other housing companies, especially those spearheading change. These examples illustrate that it is not exclusively the organisational structure-private vs. municipal-that guides institutional housing providers' practices and thus potentially limits migrants' access to the housing market.

\section{Conclusions}

In recent years, geographic and urban sociological research has started focusing on the power of (local) organisations to (re-)produce socio-spatial inequality (Allard \& Small, 2013; McQuarrie \& Marwell, 2009). One area still largely unresearched is how housing companies have reacted to the increasing diversity experienced in recent years, against a backdrop of growing sociospatial polarisation. This was the starting point for our analysis of the policies and practices of institutional housing providers in Germany and of their migrationdriven organisational change. We wanted to explore what impact institutional housing providers and their internal routines have on migrants' access to the housing market and, subsequently, on the (re)production of socio-spatial inequality. Our study clearly shows that it is not just general housing shortages that restrict migrants' access to housing in Germany. Institutional housing providers and their internal routines, but also corporate guidelines, day-to-day front-line practices and the involvement of housing companies in local government governance structures, also play a key role in (re)producing socio-spatial inequality. While our interviews reveal signs of increasing diversity driven by organisational change in housing companies, our research nevertheless illustrates that very little has yet been done to actively promote diversity in the German housing sector.

Using Lipsky's (1980) 'street-level bureaucracy' as our conceptual framework, our study reveals that the barriers denying migrants access to the rental housing market are attributable to two factors: the organisational culture and diversity policies in the form of official guidelines ('policy as written'), and the staff's day-to-day activities ('policy as performed'). Our interviews highlight a huge gap between corporate guidelines and their frontline execution, crucially hindering migration-led organisational change in the sense of facilitating access to housing for migrant households. This gap is most obvious in housing companies' HR policies, where little focus is placed on staff diversity and intercultural awareness and on the ways in which the housing companies communicate with their customers. The same applies to local governance and cooperation. Despite the increased involvement of housing companies in local cooperation projects with civil society or local authorities, it became obvious that these projects were mostly not seen as binding strategies but as 'window-dressing' and therefore had only a minor impact on making migrants' access to housing more transparent and less discriminatory.

Drilling deeper, the discrepancy between corporate guidelines on the one hand and their front-line execution on the other is also visible in housing companies' allocation policies. The interviews with employees at different levels of corporate hierarchies showed that, even when written corporate guidelines for non-discriminatory letting were available, their interpretation and execution were left very much to the discretion of front-line staff. 
For many of the latter, the sole selection criterion was 'suitability.' In most cases, written guidelines did not even exist; rather, there seemed to be an unofficial, 'unwritten' code that front-line staff were expected to follow. Thus, what Lipsky (1980) refers to as the discretionary power of front-line staff, enabling them to interpret and thus to deviate from written policies in their day-to-daywork, becomes a necessity in the face of non-existent or not sufficiently detailed allocation criteria and guidelines. Our research thus offers the opportunity to expand Lipsky's (1980) concept of 'street-level bureaucracy,' complementing it with the notion of 'forced discretion.' However, while we were able to clearly identify the (lack of) decision-making transparency and the associated discretion accorded to front-line staff as barriers hindering migrant households' access to the housing market, the interviewed housing companies viewed them as an important framework facilitating 'social engineering.' Much more awareness and engagement are therefore required at board level to critically address existing corporate policies and to develop and institutionally enshrine new allocation strategies.

Organisational change in such companies aimed at promoting equal opportunities on the housing market is achieved not just by ad hoc measures or the flagship projects proclaimed by German housing providers, but also requires new corporate policies, skills development, and decision-making transparency. For example, while our research has revealed that the dominant principle of achieving a 'healthy' (social and ethnic) mix clearly decreases migrants' opportunities to gain access to housing-especially in privileged (and Germandominated) housing estates, on the part of the institutional housing providers, no contradiction is seen between the social mix paradigm and equal opportunities in the selection of candidates. There is thus a clear gap between the empirical evidence of discrimination and the self-perception and external image of housing companies. In contrast to other European countries like England or the Netherlands, discrimination remains a taboo issue in Germany, making it more difficult to enter into a meaningful dialogue on access barriers and leading to different stakeholders not making the most of their available leeway to achieve the non-discriminatory allocation of housing.

Thus, as clearly shown in this article, local organisations such as housing companies can decisively influence the production of socio-spatial inequality. In line with McQuarrie and Marwell (2009), our research shows that organisations-here, housing companies-play a crucial role in structuring social and systemic modes of integration. To "make sense of contemporary urban change" (McQuarrie \& Marwell, 2009, p. 262), we thus need to pay more attention to the role of organisations and their internal routines. This in turn requires a better integration of organisational sociology perspectives into urban geographical and sociological research on urban segregation.
Since what people say is often only a poor predictor of what they do (Jerolmack \& Khan, 2014), our multiperspective approach involving representatives of city administrations and civil society organisations as well as reflecting on the interview findings through document analyses and focus group discussions has proved its worth. However, for future research, combining interviews with more ethnographic approaches (e.g., participatory observations) would seem to be an even more effective way of analysing the influence of local organisations and the associated organisational structures and processes in greater depth.

\section{Acknowledgments}

We would like to sincerely thank the Academic Editors of the thematic issue, Robert Barbarino, Charlotte Räuchle, and Wolfgang Scholz, as well as the four anonymous reviewers for their valuable and helpful comments on earlier drafts of this article. We are also grateful to our colleagues Christiane Droste, Carina Diesenreiter and Simon Liebig who contributed to the project and interviews this article is based on. We also disclose receipt of the following financial support for the research, authorship, and/or publication of this article: This research was supported by the vhw-Bundesverband für Wohnen und Stadtentwicklung e. V.

\section{Conflict of Interests}

The authors declare no conflict of interests.

\section{References}

Ager, A., \& Strang, A. (2008). Understanding integration: A conceptual framework. Journal of Refugee Studies, 21(2), 166-191.

Ahmed, S. (2007). 'You end up doing the document rather than doing the doing': Diversity, race equality and the politics of documentation. Ethnic and Racial Studies, 30(4), 590-609.

Allard, S. W., \& Small, M. L. (2013). Reconsidering the urban disadvantaged: The role of systems, institutions, and organizations. The ANNALS of the American Academy of Political and Social Science, 647(1), 6-20.

Antidiskriminierungsstelle des Bundes. (2019). Guide to the General Equal Treatment Act. Retrieved from http://www.antidiskriminierungsstelle.de/Shared Docs/Downloads/DE/publikationen/Wegweiser/ agg_wegweiser_engl_guide_to_the_general_ equal_treatment_act.pdf?_blob=publicationFile

Antidiskriminierungsstelle des Bundes. (2020). Rassistische Diskriminierung auf dem Wohnungsmarkt: Ergebnisse einer repräsentativen Umfrage [Racial discrimination on the housing market: Results of a representative survey]. Antidiskriminierungsstelle des Bundes. Retrieved from https://www. 
antidiskriminierungsstelle.de/SharedDocs/ Downloads/DE/publikationen/Umfragen/Umfrage_ Rass_Diskr_auf_dem_Wohnungsmarkt.pdf?_blob= publicationFile $\& v=6$

Auspurg, K., Hinz, T., \& Schmid, L. (2017). Contexts and conditions of ethnic discrimination: Evidence from a field experiment in a German housing market. Journal of Housing Economics, 35, 26-36.

Bundesverband deutscher Wohnungs- und Immobilienunternehmen e. V. (2015). Mieter mit Migrationshintergrund [Tenants with a migration background]. GdW: Berlin.

Darling, J. (2016). Asylum in austere times: Instability, privatization and experimentation within the UK asylum dispersal system. Journal of Refugee Studies, 29(4), 483-505.

Die Bundesregierung. (2007). Der Nationale Integrationsplan: Neue Wege, neue Chancen [The national integration plan: New ways, new opportunities]. Berlin: Die Bundesregierung. Retrieved from https:// www.bundesregierung.de/resource/blob/975226/ 441038/acdb01cb90b28205d452c83d2fde84a2/ 20070830nationaler-integrationsplan-data.pdf

Dill, V., \& Jirjahn, U. (2014). Ethnic residential segregation and immigrant's perceptions of discrimination in West Germany. Urban Studies, 51(16), 3330-3347.

Dobusch, L. (2017). Diversity discourses and the articulation of discrimination: The case of public organisations. Journal of Ethnic and Migration Studies, 43(10), 1644-1661.

Federal Anti-Discrimination Agency. (2006). Allgemeines Gleichbehandlungsgesetz (AGG) [German general equal treatment act]. Berlin: Federal Anti-Discrimination Agency.

Hanhörster, H. (2015). Should I stay or should I go? Locational decisions and coping strategies of Turkish homeowners in low-income neighbourhoods. Urban Studies, 52(16), 3106-3122.

Hanhörster, H., Droste, C., Ramos Lobato, I., Diesenreiter, C., \& Liebig, S. (2020). Wohnraumversorgung und sozialräumliche Integration von Migrantinnen und Migranten [Housing provision and sociospatial integration of migrants]. Berlin: vhwBundesverband für Wohnen und Stadtentwicklung e.V. Retrieved from https://www.vhw.de/fileadmin/ user_upload/08_publikationen/vhw-schriftenreihetagungsband/PDFs/vhw_Schriftenreihe_Nr._16_ Vergabepraktiken.pdf

Hanhörster, H., \& Wessendorf, S. (2020). The role of arrival areas for migrant integration and resource access. Urban Planning, 5(3), 1-10.

Helbig, M., \& Jähnen, S. (2018). Wie brüchig ist die soziale Architektur unserer Städte? Trends und Analysen der Segregation in 74 deutschen Städten [How fragile is our cities' social architecture? Trends and analyses of segregation in 74 German cities] (Discussion Paper No. P 2018-001). Berlin: WZB Wissenschaftszentrum Berlin für Sozialforschung.
Helbig, M., \& Jähnen, S. (2019). Wo findet "Integration" statt? Die sozialräumliche Verteilung von Zuwanderern in den deutschen Städten zwischen 2014 und 2017 [Where does 'integration' take place? The social-spatial distribution of immigrants in German cities between 2014 and 2017] (Discussion Paper No. P 2019-003). Berlin: WZB Wissenschaftszentrum Berlin für Sozialforschung.

Holm, A., \& Junker, S. (2019). Die Wohnsituation in deutschen Großstädten: 77 Stadtprofile [The housing situation in German cities: 77 city-profiles]. Dusseldorf and Berlin: Hans-Böckler-Stiftung.

Horr, A., Hunkler, C., \& Kroneberg, C. (2018). Ethnic discrimination in the German housing market: A field experiment on the underlying mechanisms. Zeitschrift für Soziologie, 47(2), 134-146.

Janssens, M., \& Zanoni, P. (2005). Many diversities for many services: Theorizing diversity (management) in service companies. Human Relations, 58(3), 311-340.

Jeffers, S., \& Hoggett, P. (1995). Like counting deckchairs on the Titanic: A study of institutional racism and housing allocations in Haringey and Lambeth. Housing Studies, 10(3), 325-344.

Jerolmack, C., \& Khan, S. (2014). Talk is cheap: Ethnography and the attitudinal fallacy. Sociological Methods \& Research, 43, 178-209.

Katz, M. B. (1990). The undeserving poor: From the war on poverty to the war on welfare. New York, NY: Pantheon.

Kingston, C., \& Caballero, G. (2009). Comparing theories of institutional change. Journal of Institutional Economics, 5(2), 151-180.

Kozica, A., Kaiser, S., \& Friesl, M. (2014). Organizational routines: Conventions as a source of change and stability. Schmalenbach Business Review, 66, 334-356.

Lipsky, M. (1980). Street-level bureaucracy. New York, NY: Russel Sage Foundation.

McQuarrie, M., \& Marwell, N. P. (2009). The missing organizational dimension in urban sociology. City \& Community, 8(3), 247-268.

Meziani-Remichi, Y., \& Maussen, M. (2017). Recruitment in public administrations: Diversity policies and selection practices in a French city. Journal of Ethnic and Migration Studies, 43(10), 1679-1695.

Münch, S. (2009). "It's all in the mix": Constructing ethnic segregation as a social problem in Germany. Journal of Housing and the Built Environment, 24(4), 441-455.

Pahl, R. (1975). Whose city? Harmondsworth: Penguin.

Rosen, E. (2014). Rigging the rules of the game: How landlords geographically sort low-income renters. City and Community, 13(4), 310-340.

Sala Pala, V. (2013). Discriminations ethniques: Les politiques du logement social en France et en GrandeBretagne [Ethnic discrimination: The politics of social housing in France and Great Britain]. Rennes: Presses Universitaires de Rennes. 
Statista Research Department. (2020). Statistiken zum Thema Wohnen [Statistics on housing]. Statista Research Department. Retrieved from https://de. statista.com/themen/51/wohnen

Statista Research Department. (2021). Sozialwohnungen in Deutschland bis 2019 [Social housing in Germany until 2019]. Statista Research Department. Retrieved from https://de.statista.com/statistik/daten/studie/ 892789/umfrage/sozialwohnungen-in-deutschland

Statistische Ämter des Bundes und der Länder. (2019). Wohnen in Deutschland: Zusatzprogramm des Mikrozensus 2018 [Housing in Germany: Additional programme of the micro-census 2018]. Statistische Ämter des Bundes und der Länder. Retrieved from
https://www.destatis.de/DE/Themen/GesellschaftUmwelt/Wohnen/Publikationen/DownloadsWohnen/wohnen-in-deutschland5122125189005.html

Tomlins, R. (1997). Officer discretion and minority ethnic housing provision. Journal of Housing and the Built Environment, 12(2), 179-197.

Vertovec, S. (2007). Super-diversity and its implications. Ethnic and Racial Studies, 30(6), 1024-1054.

Zhou, M. (2009). How neighbourhoods matter for immigrant children: The formation of educational resources in Chinatown, Koreatown and Pico Union, Los Angeles. Journal of Ethnic and Migration Studies, 35(7), 1153-1179.

\section{About the Authors}

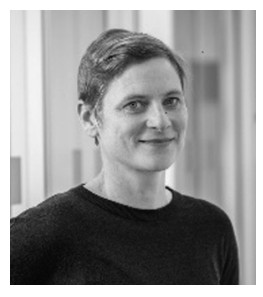

Heike Hanhörster is Senior Researcher at ILS-Research Institute for Regional and Urban Development in Dortmund, Germany. Her research interest covers place-based processes of social inclusion and exclusion and people's encounters with difference. Her recent research includes social networks of households in low-income neighbourhoods, institutional discrimination and exclusionary processes on the housing market, middle-class disaffiliation strategies as well as neighbourhood choice and affiliations of Turkish middle-class households.

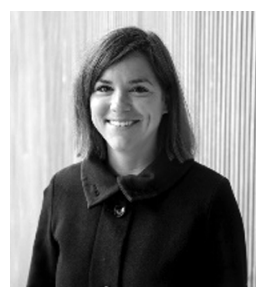

Isabel Ramos Lobato works as a Postdoctoral Researcher at the Helsinki Institute of Urban and Regional Studies, University of Helsinki, and is part of the Geographies of Education and Divided Cities (GED) research group. Her research interests are broadly rooted in urban and social geography with a focus on social inclusion and exclusion in the fields of education and housing. 